\title{
The first silesaurid dinosauriform from the Late Triassic of Morocco
}

Christian F. Kammerer, Sterling J. Nesbitt, and Neil H. Shubin

Acta Palaeontologica Polonica 57 (2), 2012: 277-284 doi: http://dx.doi.org/10.4202/app.2011.0015

Disarticulated material from the Late Triassic Timezgadiouine Formation in the Argana Basin of Morocco represents a new taxon of silesaurid dinosauromorph, Diodorus scytobrachion gen. et sp. nov. D. scytobrachion can be distinguished from other silesaurids by the presence of anteriorly-canted teeth that decrease in size towards the anterior end of the dentary and a distinct lateral ridge running parallel to the dentary alveolar margin. In a phylogenetic analysis, D. scytobrachion is recovered as the sister-taxon to the Brazilian Sacisaurus agudoensis, nested deep within Silesauridae. This new taxon provides further evidence of a near-cosmopolitan range for basal dinosauriforms in the Late Triassic and further demonstrates the disparity of dental morphologies within Silesauridae.

Key words: Dinosauromorpha, Silesauridae, Triassic, North Africa, Morocco.

Christian F. Kammerer [ckammerer@amnh.org ], Division of Paleontology and Richard Gilder Graduate School, American Museum of Natural History, New York, NY 10024, USA; current address: [christian.kammerer@mfn-berlin.de], Museum für Naturkunde, Invalidenstraße 43, 10115 Berlin, Germany; Sterling J. Nesbitt [nesbitt@ jsg.utexas.edu ], Jackson School of Geosciences, The University of Texas at Austin, Austin, TX 78712, USA; Neil H. Shubin [nshubin@uchicago.edu ], Department of Organismal Biology and Anatomy, University of Chicago, Chicago, IL 60637, USA.

This is an open-access article distributed under the terms of the Creative Commons Attribution License (for details please see creativecommons.org), which permits unrestricted use, distribution, and reproduction in any medium, provided the original author and source are credited. 
Full text $(345.2 \mathrm{kB})$ 
